Research Article

\title{
Comparative evaluation of doxofylline and theophylline in patients of mild bronchial asthma
}

\author{
Md Faiz Akram ${ }^{1,2}$, Mohammad Nasiruddin ${ }^{1}, \operatorname{Zuber}_{\text {Ahmad }}{ }^{3}$, Rahat Ali Khan $^{1}$
}

\begin{abstract}
${ }^{1}$ Department of Pharmacology, J.N. Medical College, A.M.U. Aligarh U.P. - 202002, India

${ }^{2}$ Present Affiliation at Department of Pharmacology, KMCT Medical College, P.O; Manassery, Mukkam, Kozhikode, Kerala, India ${ }^{3}$ Department of TB \& Respiratory Diseases, J.N. Medical College, A.M.U. Aligarh U.P. - 202002, India

Received: 17 April 2013

Accepted: 10 May 2013

*Correspondence to:

Dr. MD Faiz Akram,

Email: dr.faizakram@gmail.com

(C) 2013 Akram MF et al. This is an open-access article distributed under the terms of the Creative Commons Attribution License, which permits unrestricted use, distribution, and reproduction in any medium, provided the original work is properly cited.
\end{abstract}

\begin{abstract}
Background: Asthma is common chronic disease worldwide. Methylxanthines has been used in the treatment of asthma. The study was undertaken to compare two Methylxanthines theophylline and doxofylline at doses recommended and commonly used in clinical practice in Mild Bronchial Asthma Patients.

Methods: Study was conducted in patients of Mild Bronchial Asthma in TB and chest disease department of a medical college hospital. It was randomized, prospective and open label. A total of 107 patients were divided in two group .Group I was administered $400 \mathrm{mg}$ theophylline SR once daily and group II was administered doxofylline $400 \mathrm{mg}$ twice a day orally. Spirometric variables symptom score, and adverse effects were recorded on day 0, 7 and 21 of therapy. Data were compared and analysed using SPSS version 16.

Results: Results of the study showed that there was significant improvement in spirometric variables and clinical symptom score compared to pretreatment values after medication in both groups on $7^{\text {th }}$ and $21^{\text {st }}$ days of treatment. But there was no statistically significant difference between improvement in theophylline and doxofylline groups with respect to spirometric variables and symptom score. There was no significant difference in two groups with respect to side effects ( $p>0.05)$.

Conclusions: It is concluded in Patients of mild Bronchial Asthma Theophylline and doxofylline improve the spirometric and clinical symptoms and doxofylline has no advantage over theophylline in terms of either efficacy or safety on the doses commonly used in current clinical practice.
\end{abstract}

Keywords: Methylxanthines, Theophylline, Doxofylline, Mild Asthma, Bronchodilators, Histone Deacetylation

\section{INTRODUCTION}

"Asthma is a chronic inflammatory disorder of the airways in which many cells and cellular elements play a role. The chronic inflammation is associated with airway hyper responsiveness that leads to recurrent episodes of wheezing, breathlessness, chest tightness and coughing particularly at night or in the early morning. These episodes are usually associated with widespread, but variable, airflow obstruction within the lung that is often reversible either spontaneously or with treatment". (Operational definition GINA, 2012). ${ }^{1}$

It is a common chronic disease worldwide, with an estimated 300 million affected individuals. It appears that the global prevalence of asthma ranges from $1 \%$ to $18 \%$ of the population in different countries. ${ }^{2}$ In India overall prevalence of asthma has been estimated to be $2.38 \% .^{3}$ As asthma is a chronic disease the morbidity in terms of absence from school, studies and work is much. In analyses of economic burden of asthma, attention should be paid to both direct medical costs (hospital admissions and cost of medications) and indirect, nonmedical costs (time lost from work, premature death).

Methylxanthines are well known class of drugs used in asthma. They are orally effective, have bronchodilator and anti-inflammatory action and are of proven clinical effect. $^{4,5}$ Methylxanthines are important class of drug used as adjuvant in step 3 and 4 of bronchial asthma treatment. In clinical practice it is also used in cases of mild bronchoconstriction, when diagnosis of asthma is 
not certain. There are cases of Childhood Asthma and Children having episodic respiratory symptoms such as wheezing who don't have clear diagnosis of Asthma. Methylxanthines are also used by clinicians in these cases.

Theophylline (1, 3 dimethyl xanthine) most commonly used Methylxanthines. Apart from PDEs inhibition responsible for bronchodilation many other mechanisms has also been proposed specially its anti-inflammatory activity through histone deacetylases (HDAC) activation that seems to be important for Asthma inflammation. ${ }^{7}$ Bronchodilatation occurs in the serum theophylline concentration range of 5-20 $\mu \mathrm{g} / \mathrm{ml}$. Adverse reactions e.g. vomiting, headache, cardiac arrhythmias and seizures occur when peak serum concentration exceed $20 \mu \mathrm{g} / \mathrm{ml}$.

Doxofylline 7-(1, 3 dioxolane-2-yl methyl) is a newer xanthine derivatives which differ from theophylline in containing of diosalane group at position 7. Its main mechanism of action is related to non selective inhibition of phosphodiesterase enzymes like other Methylxanthines, but it has been claimed to have decreased affinities towards adenosine $\mathrm{A}_{1}$ and $\mathrm{A}_{2}$ receptors, which has been claimed as a reason for its better safety profile. ${ }^{8}$

Concern has been raised about theophylline toxicity. Current guidelines recommend use of theophylline as 100-600 mg OD sustained release tablets for Asthma that is quiet low dose. In this study a comparative clinical study for efficacy and safety between theophylline and doxofylline has been done at doses commonly used clinically. Study has been done exclusively in patients of mild Asthma (FEV1 60-80\%) to demonstrate their bronchodilating activity and improvement in clinical symptoms.

\section{METHODS}

The study was conducted in Post graduate Department of Pharmacology and of TB and Respiratory Diseases, of a medical college in India. Study was randomized, prospective, of 3 week duration. Inclusion Criteria was Patients (above 18 years of age) of Bronchial Asthma, diagnosed clinically and spirometrically, having the complaints of breathlessness, and cough. Only those patients having FEV1 ranging between $60-80 \%$ of expected were included in the study.

\section{Exclusion criteria}

Following category of patients were excluded from the study, Patient of moderate or severe Asthma (FEV1 less than $60 \%$ ), Patient with acute exacerbation of Asthma, History of Myocardial infarction, patient on antihypertensive medication, Patient on any bronchodilator drug. Any drugs having known interaction with theophylline (e.g. Warfarin, Digoxin), Pregnant and lactating mother, Patients with clinically relevant, abnormal laboratory values suggesting an unknown disease requiring further investigation.

The study protocol was approved by Institutional ethics committee of Medical College and informed consent of all patients was taken before enrolling in the study.

A Sample size was calculated from the study of Goldstein et al using \% change in FEV1 as principle variable. ${ }^{9}$ Alpha error was taken as 5\% and power of $90 \%$. Sample size came out to be 32 . Adding $10 \%$ for data loss, sample size of 35 is minimum required for each group.

A total of 120 patients were enrolled, out of which 13 patients failed to report on subsequent visits and they were excluded from the study. The remaining 107 patients were randomized into two groups at a ratio of $1: 1$ according to the table generated by random allocation software. Patients were diagnosed as a case of Asthma as per GINA guide lines. Group I was administered theophylline sustained release $400 \mathrm{mg}$ once daily and group II was administered doxofylline $400 \mathrm{mg}$ twice daily per oral. No other bronchodilator was allowed and only those patients having mild severity with $\left(\mathrm{FEV}_{1}\right)$ between $60-80 \%$ of the predicted value were included in the study.

\section{Efficacy assessments}

The efficacy of theophylline doxofylline was accessed by changes in spirometric parameters $\mathrm{FEV}_{1}, \mathrm{FVC}$ and ratio of $\mathrm{FEV}_{1} \&$ FVC. To access clinical improvement symptom score that included shortness of breath, cough, chest tightness and night time awakening with a Graded scoring system from 0 to 5 was used. Spirometric parameter and symptom score were recorded before start of therapy on day 0 for pretreatment value and then on 7 and 21 days of drug treatment. Pulmonary function tests were done by SPIROLAB II (MIR). The same spirometry equipment was used throughout the study and was performed in accordance with a Standard Operative Procedure (SOP). The pre and post treatment data of two drugs were analyzed. The data was analyzed by appropriate tests using SPSS software (version 16). For comparing Pre and post data of individual drugs paired $t$ test was used. Whereas the comparison between two groups was done using student $t$ test. As the symptom score is an ordinal data so to compare it, Mann-Whitney $\mathrm{U}$ test was applied.

\section{Safety assessments}

The adverse events experienced by patient or observed by the investigator were also recorded at each visit. Adverse drug reactions were assessed on Naranjo ADR Probability Scale and also on onset \& severity classification. Detailed physical examination, including vital signs, was performed at day 0 and at each visit. 


\section{RESULTS}

107 patients were divided in two groups. The age of patients ranged from 20 to 76 years. There were 78 males and 29 females. 21 patients $(19.6 \%)$ were smokers. With respect to pack years 14 patients $(13.08 \%)$ have smoked for $<5$ pack years, $7(6.54 \%)$ smoked for 5-10 pack years.

The results of the study showed that treatment with theophylline improved spirometric variables in Asthma patients at $7^{\text {th }}$ and $21^{\text {st }}$ day of treatment. Doxofylline 400 $\mathrm{mg}$ twice daily also showed improvement. There was statistically significant improvement in $\mathrm{FEV}_{1}$ compared to pre-treatment value in both groups. In FVC there was marginal improvement but it was not statistically significant. Mean \pm S.D. of pre and post spirometric value between of patients of group I and group II and $p$ values of different variables are detailed in (Table 1).

Table 1: Comparison of pre and post treatment spirometric variables in respective groups.

\begin{tabular}{|c|c|c|c|c|c|c|}
\hline \multirow[t]{2}{*}{$\begin{array}{l}\text { Spirometric } \\
\text { parameter }\end{array}$} & \multicolumn{3}{|c|}{ Theophylline ( $\mathrm{n}=54)$} & \multicolumn{3}{|c|}{ Doxofylline $(\mathrm{n}=53)$} \\
\hline & $\begin{array}{l}\text { Pre treatment } \\
(\text { Mean } \pm \text { S.D. })\end{array}$ & $\begin{array}{l}\text { Post } \\
\text { treatment } \\
\text { (Mean } \pm \\
\text { S.D.) }\end{array}$ & $\begin{array}{l}P \\
\text { value }\end{array}$ & $\begin{array}{l}\text { Pre } \\
\text { treatment } \\
\text { (Mean } \pm \\
\text { S.D.) }\end{array}$ & $\begin{array}{l}\text { Post } \\
\text { treatment } \\
\text { Mean } \pm \\
\text { S.D. }\end{array}$ & $\begin{array}{l}P \\
\text { value }\end{array}$ \\
\hline $\begin{array}{l}\text { FEV1 observed } \\
\text { (Lt) }\end{array}$ & $1.78 \pm 0.39$ & $2.17 \pm 0.58$ & 0.000 & $2.02 \pm 0.44$ & $2.39 \pm 0.61$ & 0.000 \\
\hline $\begin{array}{l}\text { FEV1 (\%of } \\
\text { predicted) }\end{array}$ & $71.20 \pm 4.63$ & $79.88 \pm 5.97$ & 0.000 & $70.87 \pm 4.87$ & $80.13 \pm 5.23$ & 0.000 \\
\hline FVC observed(Lt) & $2.78 \pm 0.42$ & $2.83 \pm 0.74$ & 0.084 & $3.03 \pm 0.57$ & $3.29 \pm 0.52$ & 0.128 \\
\hline $\begin{array}{l}\text { FVC (\%of } \\
\text { predicted) }\end{array}$ & $\begin{array}{l}83.82 \pm \\
5.87\end{array}$ & $84.48 \pm 6.58$ & 0.257 & $84.76 \pm 6.85$ & $86.03 \pm 6.42$ & 0.353 \\
\hline $\begin{array}{l}\text { Ratio of } \\
\text { FEV1/FVC } \\
\text { observed }\end{array}$ & $\begin{array}{l}67.43 \pm \\
3.90\end{array}$ & $77.23 \pm 3.84$ & 0.000 & $66.82 \pm 4.03$ & $75.57 \pm 5.56$ & 0.000 \\
\hline
\end{tabular}

Values are Mean $\pm S . D ; p<0.05$ taken as significant, when compared to respective pretreatment level (paired $t$ test).

Table 2: Comparison of spirometric values of patients between Theophylline and Doxofylline groups.

\begin{tabular}{|c|c|c|c|c|c|}
\hline $\begin{array}{l}\text { Spirometric } \\
\text { parameter }\end{array}$ & $\begin{array}{l}\text { Day of } \\
\text { observation }\end{array}$ & $\begin{array}{l}\text { Theophylline } \\
\text { (group1) Mean } \pm \\
\text { S.D. } \\
(\mathbf{n}=\mathbf{5 4 )}\end{array}$ & $\begin{array}{l}\text { Doxofylline } \\
\text { (group2) Mean } \\
\pm \text { S.D. } \\
(\mathrm{n}=\mathbf{5 3})\end{array}$ & $\mathrm{t}$ value & $\begin{array}{l}\text { P value Sig. } \\
\text { (2-tailed) }\end{array}$ \\
\hline \multirow{3}{*}{$\begin{array}{l}\text { FEV1 } \\
\text { observed }\end{array}$} & Day0 (Pretreatment) & $1.78 \pm 0.39$ & $2.02 \pm 0.44$ & -1.469 & 0.152 \\
\hline & Day 7 & $2.06 \pm 0.52$ & $2.38 \pm 0.57$ & -1.618 & 0.116 \\
\hline & Day 21 & $2.17 \pm 0.58$ & $2.39 \pm 0.61$ & -1.166 & 0.255 \\
\hline \multirow{3}{*}{$\begin{array}{l}\text { FEV1 } \\
\text { percentage of } \\
\text { predicted }\end{array}$} & Day 0 & $71.20 \pm 4.63$ & $70.87 \pm 4.87$ & 0.710 & 0.483 \\
\hline & Day 7 & $78.53 \pm 7.00$ & $78.47 \pm 5.55$ & 0.028 & 0.978 \\
\hline & Day 21 & $79.88 \pm 5.97$ & $80.13 \pm 5.23$ & 0.647 & 0.524 \\
\hline \multirow{3}{*}{$\begin{array}{l}\text { FVC } \\
\text { observed }\end{array}$} & Day 0 & $2.78 \pm 0.42$ & $3.03 \pm 0.57$ & -2.094 & 0.045 \\
\hline & Day 7 & $2.70 \pm 0.69$ & $3.20 \pm 0.70$ & -2.011 & 0.063 \\
\hline & Day 21 & $2.83 \pm 0.74$ & $3.29 \pm 0.52$ & -1.478 & 0.152 \\
\hline \multirow{3}{*}{$\begin{array}{l}\text { FVC } \\
\text { percentage of } \\
\text { predicted }\end{array}$} & Day 0 & $83.82 \pm 5.87$ & $84.76 \pm 6.85$ & -0.597 & 0.555 \\
\hline & Day 7 & $85.48 \pm 5.71$ & $86.96 \pm 6.22$ & -0.665 & 0.511 \\
\hline & Day 21 & $84.48 \pm 6.58$ & $86.03 \pm 6.42$ & -0.148 & 0.883 \\
\hline \multirow{3}{*}{$\begin{array}{l}\text { Ratio of } \\
\text { FEV1/FVC } \\
\text { observed }\end{array}$} & Day 0 & $67.43 \pm 3.90$ & $66.82 \pm 4.03$ & 2.708 & 0.011 \\
\hline & Day 7 & $75.00 \pm 5.00$ & $72.70 \pm 5.03$ & 1.290 & 0.207 \\
\hline & Day 21 & $77.23 \pm 3.84$ & $75.57 \pm 5.56$ & 1.909 & 0.068 \\
\hline
\end{tabular}

Values are Mean $\pm \mathrm{S}$. D; $\mathrm{p}<0.05$ is taken as significant (Student ' $\mathrm{t}$ ' test). 
But improvement recorded between theophylline and doxofylline groups were not significantly different from each other $(p>0.05)$. Mean \pm S.D. of improvement between two treatment groups of patients and $p$ values of different variables are detailed in (Table 2). The pre and post treatment values were compared by paired t test whereas the Independent-Samples t test has been used to compare means for two groups.
Regarding clinical improvement calibrated on symptom score, there was significant improvement from pretreatment value with drug treatment in both theophylline and doxofylline groups. But these improvements were not significantly different from each other $(p>0.05)$ among the two groups. Comparison of symptom scores on different days of observation is shown in (Table 3).

Table 3: Comparison of symptom score of theophylline and doxofylline groups on 0, 7 and 21 day of treatment.

\begin{tabular}{|lllll|}
\hline & $\begin{array}{c}\text { Day of } \\
\text { observation }\end{array}$ & $\begin{array}{l}\text { Theophylline } \\
\text { Group }(\mathbf{n = 5 4 )} \\
(\text { Mean } \pm \text { S.D.) }\end{array}$ & $\begin{array}{l}\text { Doxofylline } \\
\text { Group (n=53) } \\
\text { (Mean } \pm \text { S.D.) }\end{array}$ & $\begin{array}{l}\text { P value Sig. (2- } \\
\text { tailed) }\end{array}$ \\
\hline $\begin{array}{l}\text { Symptom } \\
\text { score }\end{array}$ & Day0 (Pretreatment) & $5.29 \pm 2.41$ & $5.09 \pm 2.66$ & 0.684 \\
\cline { 2 - 5 } & Day 7 & $4.26 \pm 1.39$ & $3.63 \pm 1.91$ & 0.092 \\
\cline { 2 - 5 } & Day 21 & $2.64 \pm 1.56$ & $2.23 \pm 1.56$ & 0.368 \\
\hline
\end{tabular}

Values are Mean $\pm \mathrm{S} . \mathrm{D} ; \mathrm{p}<0.05$ is taken as significant (Mann-Whitney U test).

For safety assessment Heart Rate, Blood Pressure and Adverse Drug Reaction was recorded on each visit. The results show that Heart Rate increased in both the group after drug treatment and the increase in heart rate is significantly more in theophylline group than doxofylline group. There was no significant effect on Blood Pressure
(Systolic and Diastolic) in any of the groups. Heart Rate and Blood Pressure in theophylline and doxofylline group at different days of observation has been shown in the (Table 4). As the data is continuous, IndependentSamples t test has been applied to compare on different days of observation.

Table 4: Pulse rate \& blood pressure of theophylline and doxofylline groups on different days of observation.

\begin{tabular}{|llcl|}
\hline Variables & $\begin{array}{l}\text { Theophylline Group } \\
(\mathbf{n}=\mathbf{5 4})(\text { Mean } \pm \text { S.D. })\end{array}$ & $\begin{array}{l}\text { Doxofylline Group } \\
(\mathbf{n = 5 3})(\text { Mean } \pm \text { S.D. })\end{array}$ & P value Sig. (2-tailed) \\
\hline Age (in years) & $47.84 \pm 12.54$ & $46.92 \pm 6.86$ & 0.346 \\
\hline Pulse Rate Day 0 & $77.26 \pm 5.38$ & $76.43 \pm 7.34$ & 0.417 \\
\hline Pulse Rate Day 7 & $82.01 \pm 6.86$ & $79.13 \pm 5.86$ & 0.012 \\
\hline Pulse Rate Day 21 & $81.83 \pm 8.32$ & $79.06 \pm 7.39$ & 0.018 \\
\hline B. P. Systolic Day 0 & $124.68 \pm 6.46$ & $124.82 \pm 7.39$ & 0.355 \\
\hline B.P. Systolic Day 7 & $125.07 \pm 5.71$ & $125.36 \pm 6.37$ & 0.457 \\
\hline B. P. Systolic Day 21 & $123.94 \pm 6.12$ & $124.37 \pm 6.56$ & 0.371 \\
\hline B. P. Diastolic Day 0 & $79.65 \pm 6.33$ & $80.67 \pm 4.86$ & 0.349 \\
\hline B. P. Diastolic Day 7 & $80.67 \pm 5.32$ & & 0.387 \\
\hline B. P. Diastolic Day 21 & $79.58 \pm 4.34$ & $80.32 \pm 5.26$ & 0.468 \\
\hline
\end{tabular}

Values are Mean $\pm S . D ; p<0.05$ is taken as significant. Student $t$ test has been applied.

Adverse Drug Reaction was recorded on each visit. In severity classification the adverse drug reactions were of mild in most of the cases. There was no hospitalization for adverse drug reaction in any of the cases, while proton pump inhibiters ( 6 cases in theo, 4 in doxo), antiemetic ( 3 in theo, 1 in doxo) and analgesics ( 3 in theo, 1 in doxo) has to be prescribed for dyspepsia, nausea and headache respectively. On the basis of onset of adverse event all were of sub-acute or latent in onset and no case was of acute onset (within 60 minutes). On Naranjo ADR Probability Scale the events were probable in 6 cases (Score $=5-8)$, possible (Score $=1-4$ ) in 14 cases and doubtful (Score $=0$ ) in the remaining cases. The Adverse drug reactions occurrence in theophylline and doxofylline groups and their percentage has been shown in (Table 5). 
Table 5: Number of subjects with adverse drug events and their Percentage in two groups.

\begin{tabular}{|lllll|}
\hline Side Effect recorded & \multicolumn{2}{c|}{ Theophylline group (54) } & Doxofylline group (53) \\
\hline & number & percentage & number & percentage \\
\hline Nausea & 7 & 12.96 & 6 & 11.32 \\
\hline Vomiting & 3 & 5.55 & 1 & 1.88 \\
\hline Dyspepsia & 8 & 14.81 & 7 & 13.20 \\
\hline Anorexia & 3 & 5.55 & 3 & 5.66 \\
\hline Abdominal pain & 1 & 1.85 & 0 & 0 \\
\hline Sweating & 3 & 5.55 & 4 & 7.54 \\
\hline Irregular Pulse Rhythm & 0 & 0 & 0 & 0 \\
\hline Palpitation & 5 & 9.25 & 2 & 3.77 \\
\hline Headache & 8 & 14.81 & 2 & 3.77 \\
\hline Insomnia & 3 & 5.55 & 1 & 1.88 \\
\hline Anxiety/Irritability & 2 & 3.70 & 1 & 1.88 \\
\hline Seizure & 0 & 0 & 0 & 0 \\
\hline
\end{tabular}

\section{DISCUSSION}

The results in patients show that baseline spirometric variables were similar and not significantly different in two groups. Active treatments resulted in improvements in spirometric variables which were sustained throughout the period of active treatment. The improvement in $\mathrm{FEV}_{1}$ was statistically significant from pretreatment in both groups. There was marginal increase in FVC also but it was not statistically significant. As Asthma is an obstructive condition so there is marked improvement in $\mathrm{FEV}_{1}$ but not in FVC.

But the improvement in spirometric parameter FEV1 and FVC in theophylline and doxofylline groups was not significantly different from each other $(p>0.05)$.

There are only few studies with doxofylline in mild Asthma patients and comparable studies with theophylline in mild Asthma patients are further less. Melillo $G$ et al reported a significant improvement in $\mathrm{FEV}_{1}, \mathrm{FVC}$ and other spirometric parameters in patients of reversible chronic airways obstruction. ${ }^{10}$ Marc $F$ Goldstein et al 2002 compared theophylline and doxofylline also reported an improvement in spirometric Parameter in patients. ${ }^{11}$

Most studies have administered theophylline in dose of 250-400 mg twice or thrice a day but the current recommendations for theophylline sustained release is $100-600 \mathrm{mg}$ once a day in asthma. ${ }^{12}$ So in our study the dose of theophylline sustained release was $400 \mathrm{mg}$ once daily. As theophylline has no role in acute exacerbation of Asthma but has a role in the long term management. $^{12,13}$ So sustained release tablets are considered clinically more relevant. And with this dose the improvement in spirometric variable and clinical improvement sustained throughout the period of treatment.
There were no significant finding in laboratory tests and ECG in theophylline and doxofylline groups. Heart rate increased in both the groups from baseline. The difference in the increase of heart rate was more in theophylline group than doxofylline group. There was no significant change in systolic and diastolic blood pressure recorded from baseline in both the groups at different days of observation (Table 4).

Doxofylline has produced improvements in airway obstruction comparable to theophylline. The data from this study proves that doxofylline $400 \mathrm{mg}$ twice a day was as effective as theophylline $400 \mathrm{mg}$ sustained release once a day in the treatment of Asthma. But there is nothing to suggest that it is more effective than Theophylline.

The adverse drug reactions in both the groups were mild in severity. It indicates that Concern of Methylxanthines ADRs are not of much concern at clinically used doses.

One of the major limitations of all Methylxanthines are nonselectivity for subtypes of phosphodiesterase enzyme. There is no evidence that doxofylline is selective PDE IV inhibitor. Theophylline has antagonistic action on adenosine $\mathrm{A} 1, \mathrm{~A} 2 \mathrm{a}$ and $\mathrm{A} 2 \mathrm{~b}$ receptors which are responsible for its cardiac and central nervous system stimulatory side effects. Doxofylline has been reported to have less affinity for adenosine receptor. But at clinically used doses theophylline is quiet safe and tolerable. And there is no conclusive evidence to suggest the better safety profile for Doxophylline.

On the basis of the results of the study we can conclude that efficacy of doxofylline is comparable to theophylline in cases of Asthma. Side effects of theophylline in asthma patients at dose of $400 \mathrm{mg}$ SR once daily are not of much concern. And cost effectiveness of theophylline is an added advantage. 
Recognition that theophylline has an anti-inflammatory and immunomodulatory role asthma even at low doses (plasma concentration, 5-10 $\mathrm{mg} / \mathrm{L}$ ) furthers cements its role in asthma treatment. ${ }^{14-16}$

Some more newer xanthines like acebrophylline are in market. So clinical trials to explore the interactions of doxofylline and other xanthines with corticosteroids, in asthma are thrust area of research and could lead to changes in status of xanthines in future clinical practice.

\section{ACKNOWLEDGEMENTS}

OPD staff and technical staff of pulmonary function test lab of Department of TB \& Respiratory Diseases J.N. Medical College, A.M.U. Aligarh.

Funding: Pulmonary Function Test was free in spirometry Lab of J.N. Medical College for study as per University Regulations

Conflict of interests: None declared

Ethical approval: Approved by Institutional Ethics Committee of Medical College

\section{REFERENCES}

1. Global Initiative for Asthma - Global strategy for Asthma Management and Prevention. Revised 2012 Page 16. www.ginasthma.org.

2. Masoli M, Fabian D, Holt S, Beasley R. The global burden of asthma: executive summary of the GINA Dissemination Committee report. Allergy 2004;59(5):469-78.

3. A.N. Aggarwal, K. Chaudhry, S.K. Chhabra et al. Prevalence and Risk Factors for Bronchial Asthma in Indian Adults: A Multicentre Study. Indian J Chest Dis Allied Sci 2006;48:13-22.

4. McFadden ER. Methylxanthines in the treatment of asthma: the rise, the fall, and the possible rise again. Ann Intern Med 1991;115:323-4.

5. Global Initiative for Asthma - Global strategy for Asthma Management and Prevention. Revised 2012 Page 30 www.ginasthma.org.

6. Barnes PJ, Pauwels RA. Theophylline in asthma: time for reappraisal? Eur Respir J 1994;7:579-91.
7. Ito K, Lim S, Chung KF, Barnes PJ, Adcock IM. Theophylline enhances histone deacetylase activity and restores glucocorticoid function during oxidative stress [abstract]. Am J Respir Crit Care Med 2002;165:A625.

8. Dini FL, Cogo R. Doxofylline: A New Generation Xanthine Bronchodilator Devoid of Major Cardiovascular Adverse Effects. Current Medical Research and Opinion 2001; 16:258-68.

9. Goldstein MF, Chervinsky P. Efficacy and safety of doxofylline compared to theophylline in chronic reversible asthma. Med Sci Monit 2002;8:297-304.

10. Melillo G, Balzano G, Jodice F, De Felice A, Campisi V, Capone $\mathrm{M}$, et al. Treatment Of Reversible Chronic Airways Obstruction With Doxofylline Compared With Slow Released Theophylline: A Double Blind Randomised Multicentre Trial. Int $\mathbf{J}$ Clin Pharm Res 1989;IX(6):397-405.

11. Marc F Goldstein, Paul Chervinsky. Efficacy and safety of Doxofylline compared to Theophylline in chronic reversible asthma a double blind randomized placebo controlled multicentric trial. Med Sci Monit 2002;8(4):CR297-304.

12. Global Initiative for Asthma - Global strategy for Asthma Management and Prevention. Revised 2012 Page 34 www.ginasthma.org.

13. Dahl R, Larsen BB, Venge P. Effect of long-term treatment with inhaled budesonide or theophylline on lung function, airway reactivity and asthma symptoms. Respir Med 2002;96:432-8.

14. Barnes PJ, Pauwels RA. Theophylline in asthma: time for reappraisal? Eur Respir J 1994;7:579-91.

15. Global Initiative for Asthma - Global strategy for Asthma Management and Prevention. Revised 2012 Page 34 www.ginasthma.org.

16. Evans DJ, Taylor DA, Zetterstrom O, Chung KF, O'Connor BJ, Barnes PJ. A comparison of low-dose inhaled budesonide plus theophylline and high-dose inhaled budesonide for moderate asthma. N Engl J Med 1997;337:1412-8.

doi:10.5455/2319-2003.ijbcp20130808

Cite this article as: Akram MF, Nasiruddin M, Ahmad Z, Khan RA. Comparative evaluation of doxofylline and theophylline in patients of mild bronchial asthma. Int $\mathbf{J}$ Basic Clin Pharmacol 2013;2:386-91. 